7?

columns as a simulated patient reminded me of a recent experience as a simulated candidate in the Royal College of Psychiatrists pilot objective structured clinical examination (OSCE).

Significant changes to the College Membership examinations are imminent. One of these is the introduction of an OSCE in Spring 2008 as the sole clinical component. This inevitably required training for consultants in both the theory and practice of examining an OSCE.

Specialist registrars were invited to attend as mock candidates and I arrived to find I was the only one who had done so. Luckily several of the consultants also agreed to act as candidates.

I have experienced OSCEs at first hand, both at medical school and as part of the MRCPsych part I examinations. I am familiar with the structure and have finetuned my style in the hope of improving my performance. This was not the case for many of the consultants present at the pilot.

We rotated through six linked stations, involving assessment of self-harm, schizophrenia, depression following a myocardial infarct and dementia with paranoid delusions, and preparing a court report. I was surprised by the level of anxiety I experienced but felt able to cope with this and was pleased to hear that I performed at a standard sufficient to 'pass'. What was interesting was that some of the consultants struggled to reach this standard, despite having much more clinical experience, but without any personal OSCE experience. Therefore, I feel that future candidates need to consider several factors when seeking examination practice, not least the training and actual experiences of senior clinicians.

Zoë Gilder Specialist Registrar in Child and Adolescent Psychiatry, Newcastle Child and Adolescent Mental Health Service, Tyne House, Northern Counties School and College, Tankerville Terrace, Jesmond, Newcastle uponTyne NE2 3BB, email:Zoe.Gilder@nmht.nhs.uk

doi: 10.1192/pb.31.11.435c

\section{Specialist beds for learning disability}

Lyall \& Kelly (Psychiatric Bulletin, August 2007, 31, 297-300) looked at patterns of admission for people with learning disability to specialist psychiatric beds and highlighted the lack of community resources as a cause of delayed discharge. We performed a survey of patterns of admission and characteristics of patients admitted to a 12-bedded specialist learning disability unit. This unit serves a population of 380000 . Thirty-six people were admitted over a period of 2 years and accounted for 42 admissions; 25 patients (69\%) had mild, 5 (14\%) moderate and 6 (17\%) severe learning disability. Sixteen (38\%) admissions were regarded as having delayed discharges. The mean duration of admission was 210 days but when the duration of delayed discharge was excluded this dropped to 103 days. Our experience suggests that a lack of community resources leading to delayed discharges might be more widespread.

Vikram Palanisamy Specialist Registra in Learning Disability, Cheshire and Wirral Partnership NHS Foundation Trust, Ashton House Hospital, Wirral CH43 5SR, email: drpvikram@yahoo.com, Mahesh M. Odiyoor Specialist Registrar in Learning Disability, Calderstones NHS Trust

doi: 10.1192/pb.31.11.436

\section{Safe from harm: the senior house officer experience}

Staff safety continues to be of concern in psychiatric practice. This is reflected in studies of the incidence of violence on inpatient wards (Chaplin et al, 2006) and recent recommendations from the College (Royal College of Psychiatrists, 2006). A recent study of levels of abuse experienced by specialist registrars in Northumberland (Reddy \& Kaplan, 2006) both dovetailed and contrasted with our study of violence experienced by senior house officers (SHOs).

We carried out a questionnaire survey of all SHOs on the South East Scotland training scheme in $2004(n=74)$ and repeated it in $2007(n=52)$ to ascertain the stability of our findings. A good response rate of $76 \%$ was achieved on both occasions

In 2004, 35.7\% had experienced at least one physical assault but only $40 \%$ of these had reported it. Almost all the trainees had felt at risk of violence at some time (92\%). Training in the management of aggression had been attended by $84 \%$. The findings in 2007 were broadly similar, with 35\% experiencing physical assault, $50 \%$ reporting it, and again the majority feeling at risk (87\%). Training had been attended by $72.5 \%$.

These results contrast with those of Reddy \& Kaplan for specialist registrars, of whom few (23\%) had had training but only $9 \%$ had experienced physical abuse. In our area it is the SHOs who are generally first on call for emergency assessments. We conclude that training in the management of aggression is of itself insufficient protection against assault for this relatively junior group of psychiatrists.

CHAPLIN, R., MCGEORGE, M. \& LELLIOTT, P. (2006) The National Audit of Violence: in-patient care fo dults of working age. Psychiatric Bulletin, 30 444-446.

REDDY, S. \& KAPLAN, C. (2006) Abuse in the workplace: experience of specialist registrars. Psychiatric Bulletin, 30, 379-381.

ROYAL COLLEGE OF PSYCHIATRISTS (2006) Safety for Psychiatrists (Council Report CR134). Royal College of Psychiatrists.

*Teresa O'Sullivan Specialist Registrar, Royal Edinburgh Hospital, MorningsideTerrace, Edinburgh EH10 5AF, email: osullivantreasa@aol.com, Fiona Murray Consultant Psychiatrist, St John's Hospital Livingston

doi: 10.1192/pb.31.11.436a

\section{Assessment of mental capacity}

We read with interest the article by Church \& Watts on the assessment of mental capacity (Psychiatric Bulletin, August 2007, 31, 304-307). The Mental Capacity Act 2005 came into effect in April 2007. However, are clinicians and other health professionals prepared and equipped to implement the Act? Any attempt to clarify capacity assessment as in the flow chart described by Church \& Watts is helpful. In a survey earlier this year we found that many medical professionals outside the field of mental health are unaware of the Act and have had no training in assessing mental capacity. This is highly relevant as the Act states that 'the person who is required to assess an individual's capacity will be the person contemplating making a decision on behalf of the person who is to be assessed'. Most old age psychiatrists are familiar with requests from general wards to assess 'this patient's capacity', especially when a discharge placement is in question. The Act is clear that having a psychiatric diagnosis (e.g. dementia) does not imply lack of capacity as long as the person passes the components of the capacity test. However, the Code of Practice also lists instances when an 'opinion from a professional may be required'. In the coming months will nonpsychiatric clinicians stop sending their referrals or will liaison and old age psychiatrists be flooded with requests for assessment? What is now required is clear guidance drawn up jointly by primary care, acute and mental health trusts, and training to be widely available to all professionals

*Mohammed Ashir Specialist Registrar in Psychiatry, South Essex Partnership NHS Foundation Trust,email: mohash2000@doctors.org.uk, Layth Sahib Specialist Trainee in Psychiatry (4), St Mary's Psychiatric Training Scheme, London

doi: 10.1192/pb.31.11.436b 